\title{
Genetic risk prediction using family health history approach
}

معهد دسمان للسكري

Dasman Diabetes Institute

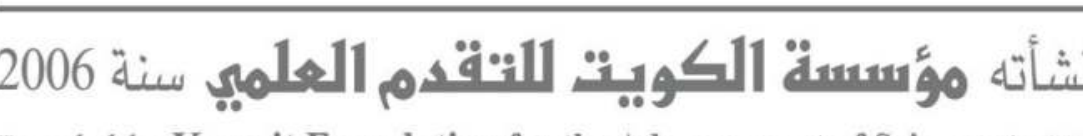

$\underline{P-0794}$

\section{Maisa Mahmoud Kamkar ${ }^{1}$, Sriraman Devarajan ${ }^{2}$, and Daisy Thomas ${ }^{1}$}

${ }^{1}$ Research Operations and Project Management Department, Research Division, Dasman Diabetes Institute, Kuwait;

${ }^{2}$ National Dasman Diabetes Biobank, Research Division, Dasman Diabetes Institute, Kuwait. Author email: maisa.mahmoud@dasmaninstitute.org

\section{Introduction}

Several genetic disorders are associated with increased risk of premature symptoms. Early detection of these disorders can help reduce the burden of common polygenic diseases such as heart diseases, hypertension, obesity, diabetes and hyperlipidemia in the persons with premature symptoms as well as in their family members. Family health history is an important risk factor implies genetic susceptibility, shared environment, and common behaviors. Obtaining a detailed family health history is considered the standard of care for characterizing the inherited component of an individual's disease risk ${ }^{1}$. The importance of family history can be emphasized by the number and variety of problems transmitted by Mendelian inheritance, multifactorial influences or chromosomal abnormalities. Genetic risk prediction is highly stable over time, as a person's genetic sequence is constant throughout their life time ${ }^{2}$.

\section{Objectives}

To evaluate usefulness of family health history to identify the presence of genetically determined disorders that may affect a person's disease risk.

\section{Methods}

Participants: A total of 544 subjects $(272$ males and 272 females) were recruited from 2011- 2013 as part of a larger obesity genetic study. Informed consent forms were obtained following the Dasman Diabetes Institute Ethical Review Committee rules and regulations. Blood samples were collected from all participants and glucose levels were measured using Cholestech LDX $^{\circledR}$. A questionnaire was developed to collect family history for five polygenic diseases cardiovascular disease (CVD), hypertension (HT), diabetes (DM), hyperlipidemia (HLP) and obesity (OBS). Demographics, medical history, lifestyle, diet and environmental risk factors were documented. Moreover, blood pressure, height, weight, waist circumference were measured.

Analysis: SPSS statistical software V.20 was used for data analysis. Initial univariate descriptive statistics were obtained for the entire study. Pearson $\chi^{2}$ test was used to examine various factors associated with presence and absence of familial polygenic diseases such as CVD, HT, DM, HLP and OBS. For all analysis $P$ value $<0.05$ was considered significant.

Family history-based risk prediction: These methods depend substantially on the extent to which an individual's family medical history is known and collected via pedigree (Figure 1).

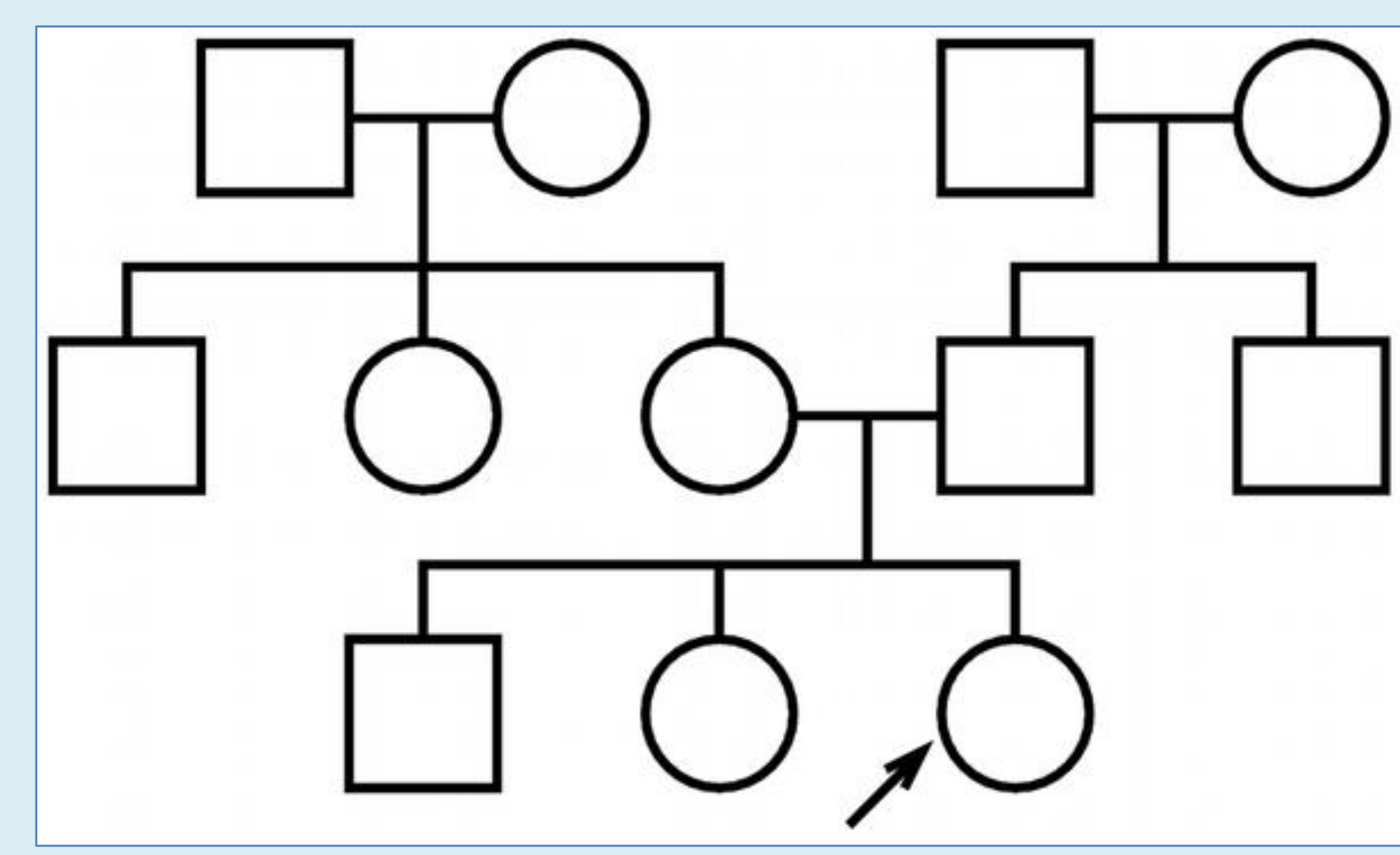

Figure 1. Test Pedigree

\begin{tabular}{|c|c|c|c|c|}
\hline \multicolumn{5}{|c|}{ Results } \\
\hline Characteristics & Male (\%) & Female (\%) & Total & $\begin{array}{c}\text { P value } \\
\text { *significant }^{2}\end{array}$ \\
\hline Participants recruited & $272(50 \%)$ & $272(50 \%)$ & 544 & --- \\
\hline Age in years (Mean $\pm \mathrm{SE}$ ) & $40.50 \pm 0.54$ & $41.66 \pm 0.60$ & & 0.1530 \\
\hline $\begin{array}{l}\text { Nationality } \\
\text { Kuwaiti } \\
\text { Non-Kuwaiti }\end{array}$ & $\begin{array}{c}89(32.7 \%) \\
183(67.3 \%)\end{array}$ & $\begin{array}{l}161(59.2 \%) \\
111(40.8 \%)\end{array}$ & $\begin{array}{l}250 \\
294\end{array}$ & $<0.0001^{*}$ \\
\hline Body Mass Index (Mean \pm SE) & $29.20 \pm 0.44$ & $32.37 \pm 0.43$ & & $<0.0001 *$ \\
\hline $\begin{array}{l}\text { Physician-diagnosed Diseases } \\
>\text { Cardiovascular Disease } \\
>\text { Hypertension } \\
>\text { Diabetes } \\
>\text { Hyperlipidemia } \\
>\text { Obesity }\end{array}$ & $\begin{array}{l}25(9.2 \%) \\
68(25.0 \%) \\
71(26.1 \%) \\
98(36.0 \%) \\
89(32.7 \%)\end{array}$ & $\begin{array}{c}17(6.2 \%) \\
79(29.0 \%) \\
86(31.6 \%) \\
93(34.3 \%) \\
149(54.8 \%)\end{array}$ & $\begin{array}{c}42 \\
147 \\
157 \\
191 \\
238\end{array}$ & $\begin{array}{c}0.1975 \\
0.2880 \\
0.1556 \\
0.6761 \\
<0.0001^{*}\end{array}$ \\
\hline $\begin{array}{l}\text { Family History: } \\
\text { > Cardiovascular Disease } \\
\text { > Hypertension } \\
\quad>\text { Diabetes }\end{array}$ & $\begin{array}{l}174(64.0 \%) \\
169(62.1 \%) \\
184(67.7 \%)\end{array}$ & $\begin{array}{l}232(85.3 \%) \\
212(77.9 \%) \\
213(78.6 \%)\end{array}$ & $\begin{array}{l}406 \\
381 \\
397\end{array}$ & $\begin{array}{l}<0.0001^{*} \\
<0.0001^{*} \\
0.0039^{*}\end{array}$ \\
\hline
\end{tabular}

Table 1. Disease risk prediction stratified by gender. Data shows that females are prone to develop polygenic diseases than males supported by significant association with the family history.

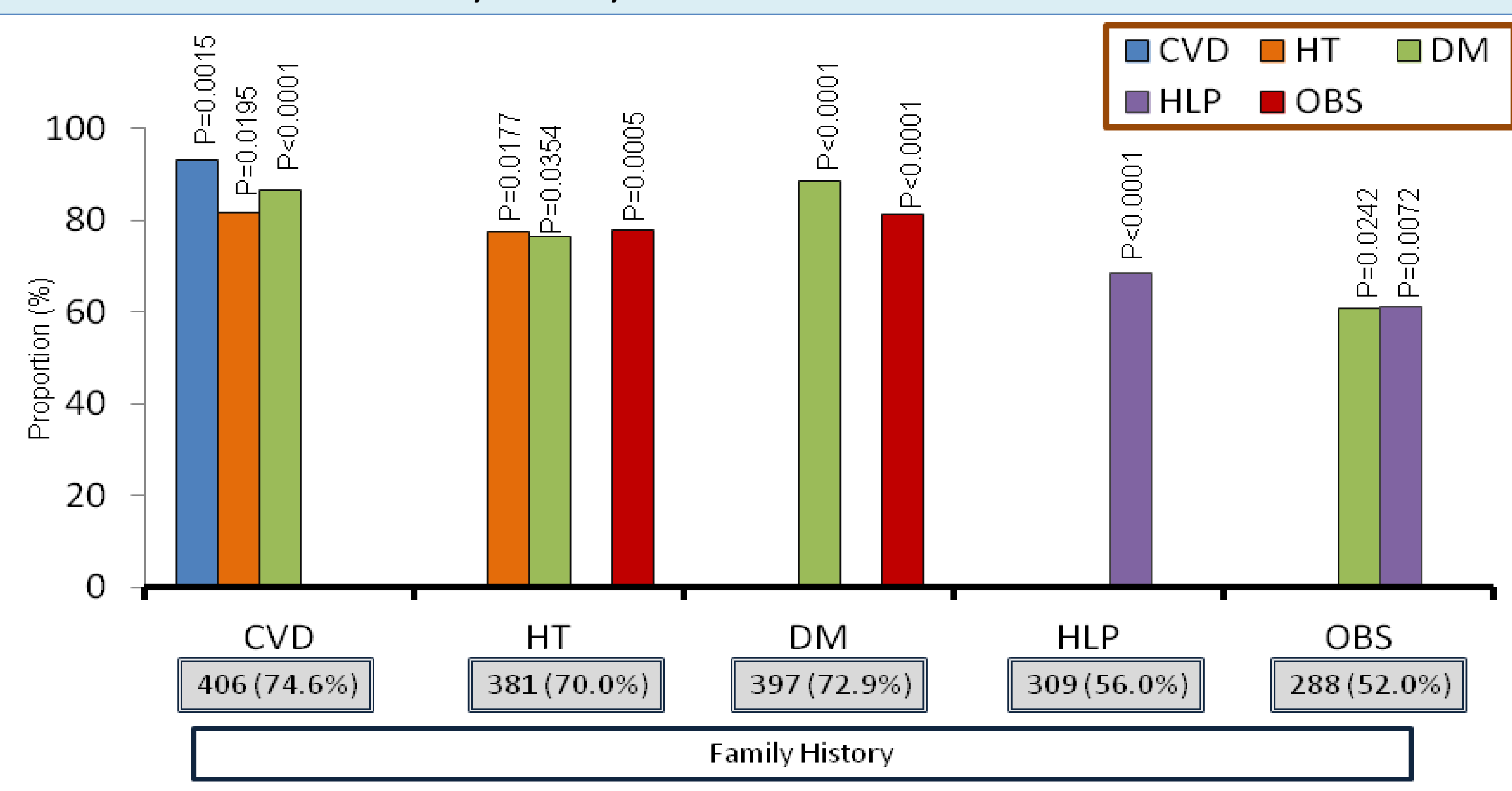

Figure 2. Disease risk prediction pattern of physician-diagnosed diseases vs. selfreporting family history. Subjects with family history of CVD had shown significant association with DM $(P<0.0001), H T(P=0.0195)$ and CVD $(P=0.0015)$; subjects with family history of $D M$ had shown significant association with $D M$ and OBS ( $P$ $<0.0001$ ); subjects with family history of HT shown significant association with DM ( $P$ $=0.0354), \mathrm{HT}(P=0.0177)$ and OBS $(P=0.0005)$; subjects with family history of HLP shown significant association with HLP $(P<0.0001)$; subjects with family history of OBS shown significant association with DM $(P=0.0242)$ and HLP $(P<0.0001)$. In summary, our data further suggesting obesity is a risk factor for these polygenic chronic disorders.

\section{Conclusions}

- A tendency toward polygenic diseases such as CVD, DM, HT, HLP and OBS can cluster in families; thus, family medical history offers important information for identifying risk in individuals.

- Risk prediction approach using family history maybe a useful tool for predicting risk of polygenic diseases which help in disease control programs.

- In the future, genetic testing for common disease such as CVD, DM, HT, HLP and OBS can be used to determine personal risk estimates.

\section{Acknowledgment}

This study was funded by Dasman Diabetes Institute, project number RA-2010-005

\section{References}

1. Do C. B. et al., Comparison of Family History and SNPs for Predicting

Risk of Complex Disease. Plos Genetics, 2012; 8: 10.

2. Jostins L. et al., Genetic risk prediction in complex disease. Human Molecular Genetics, 2011;20: Review Issue 2. 